\title{
A Guerra do sucesso pelos talentos humanos
}

\author{
Jefferson Marco Antonio Leonardo \\ Programa de Pós-Graduação em Engenharia de Produção \\ Universidade Federal de Santa Maria \\ E mail: Jleonardo@gramadosite.com.br
}

\section{Resumo}

A mudança no mundo empresarial atinge um elevado grau de inovação e agilidade, contemplando o ser humano como protagonista de uma nova história organizacional. Buscou-se constatar, na história e nas práticas atuais de administração, os referenciais de importância na gestão de recursos humanos em relação ao atendimento das necessidades e desejos dos colaboradores, como fonte estratégica de atração e retenção dos talentos humanos. A proposta para o sucesso sustentado das organizações está intimamente ligada a um redesenho na gestão de recursos humanos, transformando o atual tratamento em massa para uma gestão individualizada e diferenciada aos colaboradores, com o propósito de atender às novas exigências na retenção dos talentos humanos e da continuidade das empresas de resultados.

\section{Palavras-chave}

Talento, Recursos humanos, Modelo de gestão e Marketing individualizado.

\section{The battle of success to attract human talents}

\begin{abstract}
The change in the business world reaches a high degree of innovation and agility, contemplating human being as the protagonist of a new organizational history. We've tried to demonstrate, based on history and current management practices, the most important references, in human resources management, related to the importance of attending the necessities and desires of collaborators, as a strategic source of attraction and retain of human talents. The sustained success of organizations is closed linked to a redesign in the human resources management techniques, transforming the current mass treatment to a individualized and differentiated administration related to the collaborators, with the intent of attending to new demands on human talents retaining and continuity of results oriented companies.
\end{abstract}

\section{Key words}

Talents, Human resources, Model of management and Individualized marketing. 


\section{INTRODUĈ̣̃O}

Em toda a história do mundo empresarial, nunca houve tanta preocupação e cuidados com a retenção dos talentos de uma organização; passou-se ao patamar de ações estratégicas para o sucesso do negócio. Na visão de Drucker (1989), há evidências de um crescente desajustamento entre emprego e oferta de mão-de-obra disponível. As oportunidades de emprego ajustam-se cada vez menos às pessoas disponíveis, em razão das novas exigências qualificativas dos empregados. Os fatores tecnológicos ditam as novas necessidades de conhecimento, principalmente nos campos da informatização, robotização, automação, línguas, culturas e educação, exigindo elevados parâmetros curriculares, para que as empresas sejam, no mínimo, competitivas, caso contrário, poderão comprometer sua continuidade e/ou sua sobrevivência.

Não somente os empregos e as exigências qualificativas individuais estão mudando; as estruturas organizacionais também sofrem transformações diante das novas necessidades competitivas do mercado, as quais passaram a formatar estruturas menores, reduzindo seus níveis hierárquicos com agregação de multiespecialidades, tendo como apoio a velocidade e disponibilidade da informação.

Como exemplos desta nova posição do emprego e das pessoas, observa-se como a introdução do correio eletrônico tornou obsoletas a maioria das qualificações da secretária tradicional, como os avanços da tecnologia da robotização e de equipamentos automatizados exigiu diferenciadas qualificações na operação do trabalho, eliminando o processo manual de movimentação de materiais e outros usos desta tecnologia.

Neste contexto, Drucker (1989) descreve que o papel da mulher, do jovem e a senioridade do homem profissional também merecem apontamentos no quadro de emprego e pessoas. As mulheres, com crescentes posicionamentos e espaço no mercado de trabalho, conquistando por competência estão cargos estratégicos nas organizações, muitas vezes envolvidas no conflito entre manter-se no emprego ou ter seu primeiro ou segundo filho. Os jovens profissionais estão exigindo espaço, promoções e oportunidades para postos-chaves dentro das organizações. Em contra partida, os profissionais com mais de cinqüenta anos de idade, em início de processo para a aposentadoria, permanecem em seus postos, promovendo um desajustamento entre a realidade e as expectativas muito naturais dos jovens.

Este quadro exigirá mudanças de competências aos profissionais de recursos humanos, e novas metodologias organizacionais, com o propósito de atrair e manter profissionais com espírito empreendedor, com facilidade para promover a inovação necessária nas relações políticas, remuneração, benefícios, desenvolvimento e incentivos, dimi- nuindo o distanciamento crescente entre empregos e oferta de mão-de-obra.

O planejamento das organizações deverá contemplar novas considerações em relação às pessoas, objetivando avaliar as expectativas, aspirações, qualificações e valores das mesmas, a fim de atrair e manter seus talentos competitivos.

Na visão de Argyris (1975), faz-se necessária uma efetiva integração entre o indivíduo e a organização, a qual deverá ser conduzida pela alta administração. É importante reconhecer os diferentes interesses. Enquanto os indivíduos buscam suas satisfações pessoais através do salário, lazer, conforto, horário mais favorável de trabalho, oportunidades de carreira, segurança no cargo, etc., as organizações, do mesmo modo, têm necessidade de capital, edifícios, equipamentos, potencial humano, lucratividade, oportunidades de mercado, etc.

Dentre as necessidades organizacionais, sobressai-se a indispensável e inestimável necessidade do elemento humano, mas devemos compreender que a sobrevivência da vida de ambos está intimamente e inseparavelmente interligada, e que a integração entre pessoas e organizações é complexa, dinâmica e de reciprocidade.

\section{O HOMEM NO CONTEXTO DA ESSÊNCIA, DA HUMANIDADE E DA ORGANIZAC̄̃̃O}

Observa-se uma certa necessidade de ampliar os estudos e conhecimentos no campo da filosofia e antropologia para os profissionais especialistas em gestão de recursos humanos, com o propósito de refletir sobre a essência, a origem e o desenvolvimento do homem na humanidade e nas organizações. Para que tenhamos uma compreensão da evolução dos comportamentos e atitudes humanas na esfera pessoal e profissional, faz-se necessária uma análise aprofundada no campo do estudo filosófico e, por conseqüência, suas reflexões na esfera organizacional.

A origem do homem e da humanidade está inserida no contexto da interatividade e da adaptabilidade; "o homem não se poderia ver completamente fora da humanidade; nem a humanidade fora da vida, nem a vida fora do universo" (CHARDIN, 1993, p. 27).

De acordo com os estudos de Moraes (1998), há estimativas que datam a idade da Terra em aproximadamente 5 bilhões de anos, com o surgimento dos primeiros hominídeos entre 3 milhões e 2,5 milhões de anos atrás nos continentes africano, asiático e europeu, contemplando, na esfera física e biológica, suas maiores mudanças, evoluindo para o Homo sapiens, tornando-se capaz de compreender e controlar a natureza e, por meio do trabalho, inicialmente individualizado, transformando-a em favor de sua sobrevivência. 
Os três fatores que foram determinantes para o desenvolvimento natural do homem e sua adaptação aos diversos meios naturais foram:

1. a postura ereta, que implicou a independência das mãos;

2. a amplificação da capacidade cerebral;

3. a linguagem, que permitiu a troca e difusão de todo tipo de conhecimento.

Essa evolução se tornou rotina, porém não com a mesma rapidez dos dias de hoje, mas, como comparativo, há aproximadamente 100 mil anos, o homem Neanderthal já estava presente vivendo em cavernas, criando e desenvolvendo instrumentos mais elaborados, como o arco e flecha, anzóis, pontas de lança, e nesse período começou a controlar o fogo.

\section{crescente uso da capacidade humana viabilizará a continuidade evolutiva da humanidade.}

Essas conquistas permitiram ao homem um controle gradativo da natureza, libertando-o do modelo de sobrevivência baseado na caça, na pesca e na coleta; aprendeu a produzir e reproduzir plantas (raízes e trigo) e animais, extraindo deles carne, leite, couro e força de tração; já nesse período se dava a divisão do trabalho entre o homem e a mulher, oportunizando à mulher o exercício da criatividade através da tecelagem e produção de cerâmica, como panelas.

Para Rabuske (1986), o processo criativo foi fundamental para a sobrevivência do homem; para elucidar, criou os 5 C da criatividade: o Conhecimento, a Consciência, a Confiança, a Competência e a Coragem. Acredita-se que esses fatores foram utilizados, mas não teorizados desde os tempos da Pré-História, pois foi necessário adquirir conhecimentos, como o fogo, a alimentação, as armas e a fala, como criação de diversos recursos e a consciência da necessidade de viverem em sociedade adaptativa, utilizando-se de toda competência criativa disponível, fortalecendo a autoconfiança e a coragem das disputas para a sua sobrevivência.

Na reflexão de Predebom (1999), pode-se fazer uma relação com a história, afirmando que, no momento em que o homem aprendeu a plantar de forma coletiva e a domesticar os animais para o uso básico de sua alimentação, houve uma conseguinte acomodação no processo adaptativo da época, comprometendo a velocidade da evolução tecnológica. Comparando-se com os tempos atuais, possivelmente não haverá grandes diferenças nesse comportamento em razão dos enormes avanços e difusão da alta tecnologia, fazendo com que o homem moderno se posicione em um estágio de acomodação, deixando de criar, uma vez que suas necessidades e motivação para a mudança estão saciadas, não havendo grandes motivos para improvisar, inovar e/ou criar.

Galbraith (1986, p. 346), em seu livro A Era da Incerte$z a$ reflete que: "A dificuldade, quase que invariavelmente, está na confrontação". Será importante desenvolver soluções para o homem no futuro, compreendendo-o como ser humano profissional inserido na viabilização das organizações, com novas exigências e capacidades. $\mathrm{O}$ mesmo autor considera que a evolução da capacidade do homem é complexa e exige que os fatos sejam de seu conhecimento: "Ninguém, há duzentos anos atrás, poderia ter previsto a capacidade do homem, quer pública, social ou empresarial, de organizar-se em missões de tamanha envergadura e complexidade como a de programar uma viagem à Lua, de extrair petróleo do fundo do Mar do Norte ou de produzir uma série de filmes para a televisão" (GALBRAITH,1986, p. 331).

Robbins (1999) conceituou motivação como a vontade de empregar altos níveis de esforço em direção a metas organizacionais, condicionada pela capacidade do esforço de satisfazer alguma necessidade do indivíduo. Poder-se-ia afirmar que a motivação também está intimamente ligada à situação, sendo o resultado da interação entre o indivíduo, a situação e seu esforço de satisfazer suas necessidades.

O crescente uso da capacidade humana viabilizará a continuidade evolutiva da humanidade. "À medida em que um dos problemas é resolvido, outros surgem, geralmente a partir das próprias soluções encontradas" (GALBRAITH, 1986, p. 332).

Infelizmente, ainda hoje, com toda evolução da ciência e da tecnologia, não há uma resposta única para concluir o que somos, o que queremos e qual a nossa essência. Para Scheler (1986, p. 108), "O homem é um ser cuja própria essência é ainda uma decisão aberta - o que ele quer ser e o que ele quer se tornar".

Segundo Rabuske (1986, p. 25), de forma comparativa, acredita-se que o animal não percebe tudo como o homem: "O animal não faz descobertas, não desenvolve uma cultura, não tem história". O homem está ligado ao meio ambiente; por natureza é um ser cultural, transformável e está aberto ao mundo, exatamente como nos dias de hoje no processo da globalização.

O desafio permanente para o homem está citado por Vaz (1992, p. 146): "Uma das experiências mais constantes e mais profundas do homem é a de que a realização da própria vida, sendo para ele um desafio permanente, é, ao mesmo tempo, uma tarefa nunca acabada", sendo uma das mais penosas frustrações para o homem a sensação de uma vida não realizada, com dispersão do tempo.

Em nenhum tempo da história, o homem se tornou tão 
problemático como na atualidade. Para podermos alterar esse quadro temos que entender muito bem o homem e o seu SER humano, vitalizando ações positivas para influenciarmos a sua qualidade de vida. Todos os homens tiveram e têm uma cultura; o homem produz o produto da cultura, porém tudo interage na cultura e na constituição do mundo dos homens. A cultura, em essência, permitiu ao ser humano encontrar-se no mundo e interpretar-se a si mesmo como ser humano, orientando-o em sua vida individual e coletiva, conferindo-lhe um sentimento de aceitação.

Chanlat (1992, p. 41), em seu livro $O$ Indivíduo na Organização, descreveu uma interessante definição de cultura empresarial elaborada por Elliot Jaques: "Modo habitual de pensar e de agir", modo que "deve ser aprendido e aceito" e que é "mais ou menos compartilhado por todos os empregados da empresa". O mesmo autor considera que o reconhecimento da cultura empresarial seria um conjunto de hábitos e uma socialização geral entre todos os participantes de uma organização. As organizações são constituídas em partes e por funções essenciais de uma cultura, do enraizamento e da determinação de finalidades, viabilizando projetos, planos concretos, objetivando e permitindo a realização do sentido. O autor conceitua cultura como: "A cultura é um conjunto complexo e multidimensional de praticamente tudo o que constitui a vida em comum nos grupos sociais" (CHANLAT, 1992, p. 49).

Com esse conceito fica evidente que, para o sucesso de uma empresa (comunidade de homens), fazem-se necessárias a identificação e a interiorização da sua cultura, promovendo objetivos, metas, planos estratégicos e operacionais, criando impulsos de vontade para a efetiva ação de seus colaboradores. Se compararmos as necessidades básicas atuais do homem às dos tempos dos primatas, observaremos que não há muita diferença, como no desejo de estar inserido em uma comunidade, ser um homem pertencente à sociedade, constituir uma família, proporcionando abrigo e subsistência alimentar, viabilizando a melhor qualidade de vida possível, procurando fazer a sua história na passagem da vida de forma ética e evolutiva.

Segundo Capra (1982), a deterioração do meio ambiente está acompanhada do que o autor chamou de "doenças da civilização". Os problemas relacionados à saúde estão na esfera nutricional, nas doenças infecciosas, cardíacas e cancerígenas. No aspecto psicológico, a depressão grave, a esquizofrenia e outros distúrbios comportamentais e, no aspecto da desintegração social, os crimes violentos, acidentes e suicídios, o aumento do alcoolismo e do consumo de drogas. O mesmo autor, cita que: "Para entender nossa multifacetada crise cultural, precisamos adotar uma perspectiva extremamente ampla e ver a nossa situação no contexto da evolução cultural humana" (CAPRA, 1982, p. 24), com isso, vivemos hoje uma crise cultural; imperada pela ganância do dinheiro, pela busca do prazer, do conforto, dos bens que dão prestígio e status ao homem. Ética, em grego ethos, significa lugar de moradia, costumes, caráter e mentalidade; todas as culturas no mundo têm o seu código de moral, havendo muitos traços comuns. Em razão desta crise, o ser humano começa a sentir a necessidade de buscar bens materiais e espirituais, mas com um único propósito, sua felicidade, tentando criar sentido de prazer para sua vida pessoal e profissional sem perder o caráter ético.

$\mathrm{O}$ homem age porque um determinado objeto ou ato lhe promete prazer, e este prazer tem diversas dimensões: de intensidade, duração, segurança, imediaticidade, flutuosidade (flutuação para outros prazeres), pureza (de dor e incômodo) e extensão (para outros indivíduos); com tais dimensões se torna mais visível o sistema situacional e adaptativo do homem moderno.

Estamos vivendo a era do conhecimento, mas com ela um paradoxo interessante consiste no fato de que o ser humano nunca teve tanto acesso à informação, ao mesmo tempo em que nunca teve tão pouca certeza de si próprio.

Vivemos um mundo de transformações desde a PréHistória até a nossa idade moderna, mas não é somente uma transformação de coisas, de circunstâncias, de instituições, de conceitos e de formas fundamentais da arte e de todas as ciências: é transformação do próprio homem, da natureza da própria constituição interna de seu corpo, de seus impulsos, de sua alma e de seu espírito; e não somente uma transformação do seu ser atual, mas também das suas escalas de valor.

\section{AS ESCOLAS E TEORIAS DA ADMINISTRAC̣ÃO NO CONTEXTO DO HOMEM PROFISSIONAL}

\section{Escola Tradicionalista}

A perspectiva da administração, nas décadas iniciais do século XX, focou a tentativa por uma melhor engenharia humana para a racionalização do modo como o trabalho se concretizava, com ênfase no aumento da produtividade.

Para Cury (2000), as práticas administrativas desse período concentravam-se na análise das atividades das empresas, nos estudos de estrutura e da departamentalização. Esse enfoque foi denominado de Escola Tradicionalista, também conhecida como Mecanicista ou de Administração Científica, sendo os seus principais integrantes Heri Fayol, Frederick W. Taylor, Luther Gulick, James Mooney e Lyndal Urwick.

A vulgarização do trabalho de Taylor propagou uma visão de eficiência baseada em redução de custos unitários e aumento da produção. Isso resultou em atividades monótonas, supervisão rígida por pessoas cuja autoridade se 
fundamentava apenas na posição hierárquica e cargos cujo único aspecto atraente era o salário que pagavam. Essa escola acredita que os empregados acham o trabalho desagradável, dão mais valor a recompensas financeiras e poucos deles são capazes de trabalhos criativos.

Taylor exclui totalmente o indivíduo do processo de decidir sobre o que fazer, como fazer, por que fazer, tornando-o apenas um homem trabalhando como um apêndice da máquina, considerando-o apenas como recurso. ção do homem ao trabalho, procurando tornar o trabalho mais agradável e compensador, implementando atividades extrafuncionais, como os intervalos de trabalho, refeições no restaurante da fábrica, associações de empregados, torneio de esportes, excursões, folhetos ou boletins de empregados, salões de jogos, colônias de férias, etc. Assim, o trabalho tornou-se um sacrifício compensado pela felicidade a ser gozada fora dele.

Douglas MacGregor, citado por Balcão \& Cordeiro (1975, p. 45), afirma que: “...a indústria já possui os conhecimentos fundamentais para a utilização das ciências físicas e da tecnologia em benefício material da humanidade e que agora precisamos aprender a utilizar as ciências sociais para fazer com que as organizações humanas se tornem realmente eficientes".

Ainda de forma muito tímida, observam-se, nesta escola,

Talvez a maior influência de Taylor na sociedade seja a sua visão de produção em massa, de padronização de procedimentos, que superou os limites das organizações industriais e passou a fazer parte da vida social. Somos ainda hoje tratados de forma padrão, como uma massa indivisível de pessoas, todos sendo atendidos por sistemas projetados segundo as premissas da eficiência e eficácia máximas. Isso significa que, mesmo sendo filosoficamente reconhecida a importância de cada ser humano ser tratado como indivíduo, um EU único, nossos sistemas sociais não o fazem, tratando-nos como mais um número em estatísticas, desconhecendo nossa história, interesses e necessidades específicas.

\section{Escola de Relações Humanas}

A escola de relações humanas emergiu, na década de 20, da série de experimentos na fábrica da Western Electric em Hawthorne, que procurou determinar como a produtividade era afetada pelas condições de trabalho. Os pesquisadores concluíram que os trabalhadores respondem mais à maneira como são tratados do que às mudanças nas condições ambientais e que quanto maior o nível de integração social no grupo de trabalho e com a liderança, tanto maior a disposição de produzir e aumentar a produtividade. Nos Estados Unidos surgiu, em parte, como reação à Administração Científica, a Escola de Relações Humanas, que acentuou os elementos emocionais, não-planejados e irracionais do comportamento na organização, descobrindo o significado da amizade, do agrupamento social dos trabalhadores, a importância da liderança, da comunicação e da participação emocional na organização.

A escola das relações humanas concentrou-se na integra- os primeiros passos para a observação e o atendimento de outras necessidades do trabalhador, criando e implantando ações coletivas, mas resultando em satisfações individualizadas.

A evolução das relações humanas nas organizações referenda o atual sucesso nos resultados de diversas empresas, colhendo frutos para a sua continuidade e o seu desenvolvimento empresarial. Portanto, faz-se necessário relatarmos, de forma compacta, esta evolução, agregando-se a importância da área de recursos humanos nesse processo.

Toledo (1989) inicia o relato da evolução das relações humanas no período da revolução industrial como um momento triste e sombrio do mundo industrial, no qual crianças de 4 a 5 anos já estavam sentadas nas bancas de trabalho, promovendo uma enorme desarmonia nas relações humanas e a auto-realização dos trabalhadores comparativamente à época do trabalho artesanal.

$\mathrm{O}$ trabalho artesanal, que durou apenas quatro séculos (do XI ao XV), era composto, inicialmente, por membros da mesma família, dedicados à fabricação de determinadas mercadorias, liderados por um mestre, que se caracterizava pela experiência e habilidade no ofício. Aprendendo com esses mestres e auxiliando-os, posicionavam-se os aprendizes, e entre as duas posições funcionais havia uma terceira, chamada de oficiais (ex-aprendizes e futuros mestres).

Nesse núcleo de trabalho evidenciava-se o estabelecimento das relações humanas no trabalho, que é chamado pela ciência sociológica de relações primárias, devendo ser compreendido como o simples prazer de manter um contato

\section{Evolução Histórica das Relações Humanas}


entre duas pessoas, sem visar interesses imediatos ou materiais, embebido de afetividade e escasso de atritos.

Observa-se que certos desejos básicos da pessoa, como o de consideração, estabilidade, afetividade, reconhecimento individual e outros, eram satisfeitos de maneira adequada nessa realidade social e econômica.

As descobertas dos séculos XV e XVI, o movimento renascentista, o mercantilismo, as possibilidades tecnológicas, as aplicações de capitais, a fermentação comercial e outras causas influenciaram o desequilíbrio da era artesanal, emergindo a revolução industrial, com significativos ganhos econômicos, mas com primorosas perdas psicossociais conjugadas à desvalorização das habilidades e capacidades profissionais. O hábil artesão anulou-se na criação de um artigo; passou simplesmente a colaborar inconsciente e mecanicamente com um produto, havendo a diminuição do orgulho pelo trabalho em razão de não mais ser fruto do seu próprio esforço. $\mathrm{O}$ fato de haver um grande número de pessoas concentradas em uma mesma atividade proporcionou a descontinuidade dos contatos primários existentes no núcleo artesanal.

Os papéis e posições foram alterados; o mestre, de orientador, professor e mentor passou a ser o fiscal, vigia, e/ou os olhos do patrão, afastado da linha de produção. Nesse novo processo as relações entre as pessoas passaram a ser secundárias, ou seja, baseadas no interesse ou na necessidade de serem mantidas no trabalho, sem afetividade e sem relacionamento individualizado. A linguagem no mundo industrial dirigiu-se para dois tipos: a da gerência e a do executor, delineando-se o ambiente organizacional ainda predominante nos dias atuais.

\section{O Surgimento do Órgão de Recursos Humanos}

Para Toledo (1989), o surgimento do órgão de recursos humanos como área definida na estrutura organizacional deu-se no início do século passado, com uma forte alavancagem evolutiva nos anos 20 , com o fortalecimento do movimento sindical devido às conseqüências econômicas e sociais negativas provocadas pela Revolução Industrial, exigindo um tratamento e administração diferenciada do fator humano no trabalho. Outro fator contributivo foi a escassez de mão-de-obra provocada pela Primeira Guerra Mundial.

As ações iniciais da administração de recursos humanos foram tendenciosamente paternalistas, voltadas a programas de bem-estar social, visando a afastar a hostilidade sindical. Nos anos trinta, através dos movimentos filosóficos, o pensamento existencial, os trabalhos de Sociologia do Trabalho, os experimentos de Hawthorne, na Western Electric, nos Estados Unidos, foram determinantes éticos e científicos para um novo salto na evolução da administração de recursos humanos.
Nesse novo momento, juntamente com as pesquisas realizadas, observou-se que as relações humanas, seus estados em expressões individuais e grupais, afetavam profundamente a produtividade, resultando na seguinte premissa: “...melhorem-se as relações humanas dentro de uma empresa, e melhoraremos a produção; satisfaçam-se os desejos espirituais básicos do homem, tais como o de consideração, estabilidade, afetividade e outros, e teremos um aumento da harmonia produtiva" (Toledo, 1989, p. 21).

Para Werther \& Davis (1983), com este movimento, os desafios da sociedade se tornaram mais complexos, havendo por parte das organizações uma resposta crescente de técnicas de relações humanas, apoiadas nos conhecimentos sociológicos e psicológicos acumulados. A comprovação da influência direta nos resultados da organização e as possibilidades de desenvolvimento de novas aplicações das técnicas de relações humanas valorizaram, de forma significativa, a área de recursos humanos, transformando sua missão inicial de servir de amortecedor das insatisfações de pessoal para um órgão de contribuição efetiva na modernização constante das organizações como um todo.

Como exemplo dessa modernização, podemos citar a elaboração e implantação da Administração por Objetivos e os produtos da psicologia organizacional, principalmente no desenvolvimento organizacional.

A evolução e as mudanças também se projetaram com a nomenclatura da área, que inicialmente era chamada de Administração de Pessoal, passando para Relações Industriais, em seguida para Recursos Humanos. Atualmente algumas organizações utilizam-se de nomenclaturas com adjetivos de: potencial e desenvolvimento humano.

Como perspectivas do desenvolvimento da administração de recursos humanos, visualiza-se a crescente humanização das relações de trabalho com a criação de climas de trabalho que permitam a realização plena do ser humano como pessoa, fortalecendo a ampla auto-realização pessoal, o seu desenvolvimento e a motivação do pessoal, com impacto direto nos resultados da empresa.

\section{Função e Objetivo de Recursos Humanos}

Para Werther \& Davis (1983), os especialistas de pessoal devem guiar-se pelo propósito da administração de recursos humanos, que é: prover as organizações com uma força efetiva de trabalho, entendendo que o principal pilar de sustentação do sucesso organizacional são as pessoas. Além desse propósito, faz-se necessário direcionar-se por quatro objetivos básicos: a) Objetivo societário: ser socialmente responsável perante as necessidades e desafios da sociedade; b) Objetivo organizacional: fazer da administração de recursos humanos um prestador de serviços a toda a organização; c) Objetivo funcional: manter a contribuição da administração de recursos humanos em um nível apropria- 
do; d) Objetivo pessoal: dar assistência aos empregados na consecução de suas metas pessoais para que eles possam ser mantidos e retidos, aumentando a contribuição do indivíduo para a organização.

Por muito tempo, na história da evolução da administração, o homem foi considerado apenas mais um recurso; “... o homem nada mais era que uma máquina que operava outra máquina" (BALCÃO; CORDEIRO, 1975, p. 78).

O quarto objetivo da administração de pessoal, citado pelos autores, deixa clara a principal tarefa do especialista de recursos humanos, a assistência às pessoas que trabalham na organização, conjugando as necessidades técnicas organizacionais e principalmente as necessidades pessoais, objetivando a satisfação do colaborador, estimulando-o a permanecer na empresa e contribuir com seu sucesso.

Para Toledo (1989), a função da área de recursos humanos constitui-se nas amplas ações de gerenciar, administrar ou gerir, igualmente como é a função de marketing, financeira, produção, etc. Um dos conceitos de gerência é a ação que implica direção, coordenação e controle de recursos; entre eles, os recursos humanos. Com esse conceito, fica evidente que todo e qualquer gerente, supervisor ou líder, é também responsável pela função de recursos humanos.

A função de recursos humanos pode ser classificada como atividades de atração, manutenção, motivação, treinamento e desenvolvimento do pessoal de um grupo de trabalho. Vale observar que, antes do surgimento do órgão de recursos humanos, as chefias, a fim de desempenharem suas funções, atuavam diretamente na escolha de pessoal (ações de atração), na administração dos níveis de remuneração (ações de manutenção), na avaliação do rendimento e incentivo (ações de motivação), finalmente, ensinando e desenvolvendo seus subordinados.

Com o surgimento do órgão de recursos humanos, este passou a executar uma parcela dessas funções, desenvolvendo instrumentação técnica mais adequada, sendo utilizada pela própria área de recursos humanos, como também pelos gerentes e líderes em geral.

As funções de recursos humanos, nos dias atuais, têm importante ação no assessoramento da alta direção da empresa, transformando-se em agente de mudanças, contribuindo, com a modernização da estrutura organizacional, na metodologia e estilo gerencial das organizações.

Para Caravantes (1993), novos componentes na metodologia gerencial, como conhecimento, informação, criatividade, habilidades interpessoais e habilidades de empreender, são importantes para o sucesso de uma organização, implicitamente desafiadores para a área de recursos humanos, que terá agregado, em suas funções, a preparação eficaz desses novos componentes, desenvolvendo seus líderes e suas equipes, contribuindo com um fator de diferenciação na competitividade empresarial.

\section{Teoria Estruturalista}

A teoria estruturalista foi a primeira teoria da administração a reconhecer que o conflito entre os objetivos individuais e os objetivos organizacionais não poderia ser solucionado, apenas administrado. Foi também a primeira teoria a tratar de ambos os aspectos das organizações: tanto o formal, quanto o informal. Nasceu da oposição existente entre a escola clássica e a escola de relações humanas, pois sentiu-se a necessidade de "uma posição mais ampla e compreensiva, que abrangesse os aspectos que eram considerados por uma e omitidos pela outra e vice-versa" (CHIAVENATO, 2000, p. 344).

De forma conceitual, estruturalismo é um método analítico e comparativo que estuda os elementos ou fenômenos com relação a uma totalidade. Entende-se como estrutura a análise interna de uma totalidade em seus elementos constitutivos, sua disposição, suas inter-relações. O todo é maior do que a soma das partes e qualquer alteração em uma das partes irá conseqüentemente refletir-se no todo.

Esta teoria traz o conceito de homem organizacional, que, para ser bem-sucedido em todas as organizações, precisa ter as seguintes características de personalidade, segundo Chiavenato:

Flexibilidade, em face das constantes mudanças que ocorrem na vida moderna, bem como da diversidade dos papéis desempenhados nas diversas organizações, que podem chegar à inversão, aos bruscos desligamentos das organizações e aos novos relacionamentos.

Tolerância às frustrações para evitar o desgaste emocional decorrente do conflito entre necessidades organizacionais e necessidades individuais, cuja mediação é feita através de normas racionais, escritas e exaustivas, que procuram envolver toda a organização.

Capacidade de adiar as recompensas e poder compensar o trabalho rotineiro dentro da organização, em detrimento das preferências e vocações pessoais, por outros tipos de atividade profissional.

Permanente desejo de realização para garantir a conformidade e cooperação com as normas que controlam e asseguram o acesso às posições de carreira dentro da organização, proporcionando recompensas e sanções sociais e materiais (CHIAVENATO, 2000).

Apesar dessas observações, não foram identificadas situações em que os indivíduos fossem tratados de forma individual dentro desta teoria; a pressuposição de homem organizacional nos traz a idéia de que o homem deve adaptar-se aos procedimentos e exigências organizacionais, enquanto a organização não possui a preocupação de adaptar seu comportamento às necessidades de seus colaboradores. A própria definição de estruturalismo nos traz a idéia de que a estrutura é permanente, enquanto seus ocupantes não. 


\section{Teoria Comportamental}

Abordaremos algumas teorias comportamentais, de forma sintética, com o propósito de salientar as necessidades motivadoras do ser humano, no campo organizacional.

Wagner \& Hollenbeck (2000, p. 6), consideram o crescimento do conhecimento no campo comportamental utilizado nas organizações, principalmente pela área de recursos humanos, por muitas vezes, colaborando nas soluções dos problemas motivacionais. Os autores citam que: "a administração de recursos humanos mediante a aplicação de conhecimento no campo do comportamento organizacional é, portanto, um recurso essencial com o qual é possível criar e manter vantagem competitiva".

\section{- Fatores intrínsecos e}

\section{extrínsecos de Frederick Herzberg}

A teoria dos dois fatores foi desenvolvida a partir do estudo de entrevistas realizadas com 200 engenheiros e contadores da indústria Pittsburgh, com o objetivo de identificar os fatores de felicidade e infelicidade dos trabalhadores na situação de trabalho.

Segundo Caravantes (1998, p. 78), os estudos de Herzberg concluíram que: "O oposto de satisfação profissional não seria a insatisfação, mas sim nenhuma satisfação profissional; e da mesma maneira, o oposto de insatisfação profissional seria nenhuma insatisfação profissional e não a satisfação". Motivadores são os fatores que fazem a pessoa sentir-se bem no trabalho. Esses fatores são inerentes à própria pessoa ou ao trabalho em si, isto é, intrínsecos: (a) realização, (b) reconhecimento, (c) trabalho em si, (d) responsabilidade, (e) progresso e (f) crescimento.

Higiênicos são os fatores cuja ausência provoca malestar. Esses fatores são relacionados à organização e ao ambiente externo, isto é, extrínsecos: (a) diretrizes e administração da empresa, (b) supervisão, (c) relacionamento com superiores, (d) condições de trabalho, (e) salário, (f) relacionamento com colegas, (g) vida pessoal, (h) relacionamento com subordinados, (i) status e (j) segurança.

\section{- Teoria ERC de Clayton Alderfer}

O autor Robbins (1999, p. 112), em seu livro Comportamento Organizacional, cita que: "Alderfer argumenta que existem três grupos de necessidades centrais - existência, relacionamento e crescimento - daí o nome: teoria ERC". O mesmo autor explica que existem três grupos de necessidades essenciais, sendo que mais de uma necessidade pode estar operante ao mesmo tempo:

Existência: exigências básicas para a existência material. Equivale aos elementos fisiológicos mais segurança de Maslow.
Relacionamento: desejo de relacionamentos interpessoais significativos. Equivale aos fatores sociais e ao componente social da auto-estima de Maslow.

Crescimento: desejo de desenvolvimento pessoal. Inclui aspectos intrínsecos da auto-estima mais a realização de si mesmo de Maslow.

Quando uma pessoa é bloqueada na satisfação de um nível mais alto, ela regride, aumentando necessidades de nível mais baixo. Por exemplo, se o crescimento profissional é frustrado, ela vai se preocupar mais com salário. az-se urgente o rompimento dos métodos tradicionais de recursos humanos, em prol de uma redefinição das técnicas de gestão da empresa e da administração de recursos humanos.
Fatores culturais podem mudar a influência dos fatores. Por exemplo, no Japão e na Espanha, os fatores sociais são mais importantes que os fisiológicos.

\section{- Necessidades de McClelland}

Descrita por Robbins (1999, p. 113), a teoria de necessidades de McClelland foi desenvolvida por David McClelland e seus associados. Em sua pesquisa sobre necessidade de realização descobriu que: "indivíduos altamente realizadores diferenciavam-se dos outros pelo seu desejo de fazer as coisas de forma melhor". O mesmo autor complementa que as pessoas podem possuir em maior ou menor grau três tipos de motivação:

Realização: desejam sucesso em suas atividades. Para elas, a realização pessoal é mais importante do que as recompensas. Procuram fazer as coisas da melhor maneira possível, superando a si mesmas e aos outros .

Poder: desejam causar impacto sobre as pessoas. Querem ser influentes, controlar o comportamento dos outros. Gostam de prestígio, competição, status. Sua preocupação com desempenho é secundária.

Afiliação: desejam ser apreciadas, estimadas e aceitas pelos outros. Buscam amizade, preferem cooperação a competição, apreciam situações onde há compreensão mútua.

Os realizadores são bons empreendedores, mas nem sempre são bons gerentes. Os gerentes das grandes empresas geralmente possuem alta necessidade de poder e baixa necessidade de afiliação. 


\section{- Teoria de Determinação de Metas}

No final dos anos 60, Edwin Locke propôs que: "as intenções de trabalhar em direção a uma meta são a principal fonte de motivação de trabalho" (ROBBINS,1999, p. 115). As pessoas são motivadas pelas metas estabelecidas:

Metas bem definidas são mais estimulantes do que genéricas (tipo: "faça o que puder!" ou "dê o melhor de si!").

Desde que haja capacidade e aceitação, quanto mais ambiciosa a meta, maior o desempenho. Desde que haja aceitação, metas estabelecidas por outros (por ex., um líder) são tão motivadoras quanto metas estabelecidas pela própria pessoa.

Segundo Robbins (1999), a participação no estabelecimento das metas contribui para sua aceitação e supera resistências. As pessoas se comprometem quando participam das decisões quanto às metas.

As pessoas têm desempenho melhor quando recebem feedback. Feedback gerado por elas mesmas tem mais efeito que feedback recebido de outros. O desempenho é melhor quando as pessoas têm condições de avaliar por si mesmas os resultados de seu trabalho.

\section{- Teoria da equidade}

No conceito de Robbins (1999), a teoria da equidade se alicerça na comparação que as pessoas fazem entre o esforço que estão aplicando ao trabalho e as recompensas que estão obtendo. Podem tomar como comparação pessoas dentro ou fora da mesma empresa, situações passadas ou oportunidades de outros empregos. Quando percebem uma situação injusta, procuram compensar, mudando o esforço ou tentando mudar o contexto (ex.: trocar de emprego).

\section{- Teoria da expectativa de Victor Vroom}

Para Robbins (1999, p. 118), atualmente uma das explicações de motivação mais amplamente aceitas é a teoria da expectativa. As evidências da pesquisa de Victor Vroom sustentam que: "A teoria da expectativa argumenta que a força de uma tendência para atuar de uma certa forma depende da força de uma expectativa de que o ato será seguido por um dado resultado e da atração que aquele resultado exerce no indivíduo". O mesmo autor explica que a motivação depende de como a pessoa percebe três relações de causa e efeito:

1. Esforço x Desempenho: a pessoa acredita que com mais esforço pode melhorar o desempenho.

2. Desempenho x Recompensa: a pessoa acredita que o desempenho produzirá uma recompensa determinada.

3. Recompensa $x$ Metas pessoais: à medida em que as recompensas oferecidas pela organização são atraentes para a pessoa.
Esta teoria explica porque muitos empregados se esforçam pouco, limitando-se a fazer o mínimo. Quantas pessoas responderiam sim a estas três perguntas?

- Se eu me esforçar mais, serei recompensado?

- Se meu desempenho for reconhecido, serei recompensado por isso?

- Se for recompensado, as recompensas valerão a pena?

\section{- A hierarquia das necessidades de Maslow}

Segundo Wagner \& Hollenbeck (2000), o psicólogo Abraham Maslow formulou um modelo da motivação humana que exerce grande influência sobre o pensamento administrativo. Esse modelo considera que as necessidades humanas organizam-se segundo uma hierarquia: fisiológicas, segurança, associação, status e auto-realização, na qual as necessidades de nível mais baixo prevalecem sobre as de nível mais alto.

Necessidades fisiológicas: constituem o nível mais baixo de todas as necessidades humanas, mas são de vital importância. Neste nível estão as necessidades de alimentação, de sono, de abrigo, o desejo sexual, etc. Estão relacionadas com a sobrevivência do indivíduo e com a preservação da espécie.

Necessidades de segurança: são as necessidades de segurança ou estabilidade, a busca de proteção contra a ameaça ou privação, a fuga ao perigo. Surgem no comportamento quando as necessidades fisiológicas estão relativamente satisfeitas. Têm grande importância no comportamento humano, uma vez que todo empregado está sempre em relação de dependência com a empresa, na qual ações administrativas arbitrárias ou decisões incoerentes podem provocar incerteza ou insegurança no empregado quanto à sua permanência no emprego.

Necessidades sociais: surgem quando as necessidades mais baixas (fisiológicas e de segurança) se encontram relativamente satisfeitas. São necessidades de associação, de participação, de aceitação por parte dos companheiros, de afeto e de amor. Quando estas necessidades não estão suficientemente satisfeitas, a pessoa torna-se resistente, antagônica e hostil com relação às pessoas que a cercam. A falta de amor e de afeição conduz à falta de adaptação social e à solidão.

Necessidades de estima: estão relacionadas com a maneira pela qual o indivíduo se vê e avalia. Envolve autoapreciação, autoconfiança, necessidade de aprovação social e de respeito, de status, de prestígio e de consideração. A frustração desta pode produzir sentimentos de inferioridade, fraqueza, dependência e desamparo.

Necessidades de auto-realização: são as necessidades mais elevadas. São as necessidades de cada pessoa realizar o seu próprio potencial e de autodesenvolver-se continuamente. Essa tendência geralmente se expressa através do 
impulso de a pessoa tornar-se sempre mais do que é e de vir a ser tudo o que pode ser.

A Figura 1 retrata, em formato gráfico, a pirâmide hierárquica das necessidades humanas, desenvolvida por Maslow sendo amplamente utilizada nos processos e metodologia de liderança e trabalhos em equipe, como ferramenta de gestão de pessoas, evidenciando-se o sistema situacional.

$\mathrm{O}$ processo de liderança está intimamente ligado ao estado e/ou posicionamento situacional do liderado, de acordo com suas necessidades presentes, que flutua conforme suas ocorrências internas e externas, interferindo diretamente no resultado final da organização e do profissional.

Para Wagner \& Hollenbeck (2000), cada pessoa possui sempre mais de uma motivação. Todos os níveis atuam conjuntamente no organismo, as necessidades mais elevadas dominando as mais baixas, desde que estas estejam suficientemente satisfeitas ou atendidas.

Qualquer frustração ou ameaça da satisfação passa a ser considerada ameaça psicológica. Essa ameaça é que produz as reações gerais de emergência no comportamento humano.

\section{RETENÇÃO DE TALENTOS COMO ESTRATÉGIA COMPETITIVA}

No contexto organizacional a empresa participa com remuneração, segurança, status e outros, e reciprocamente o colaborador responde trabalhando, desempenhando suas tarefas; a organização espera que o empregado obedeça à sua autoridade, e o empregado espera que a organização se comporte corretamente com ele e opere com justiça. Com esse processo, forma-se um contrato psicológico de expectativa recíproca, indo muito além de qualquer contrato formal de emprego que estabeleça o trabalho a ser realizado e a recompensa a ser recebida.

O contrato psicológico é um elemento importantíssimo na relação de trabalho, que influencia consideravelmente o comportamento das partes, sendo sempre avaliado pelo que está oferecendo e o que está recebendo em troca.

Para Chiavenato (1992), sempre existe um relacionamento de intercâmbio entre os indivíduos e a organização; o modo pelo qual os objetivos individuais são satisfeitos

Figura 1: Pirâmide da Hierarquia das Necessidades de Maslow

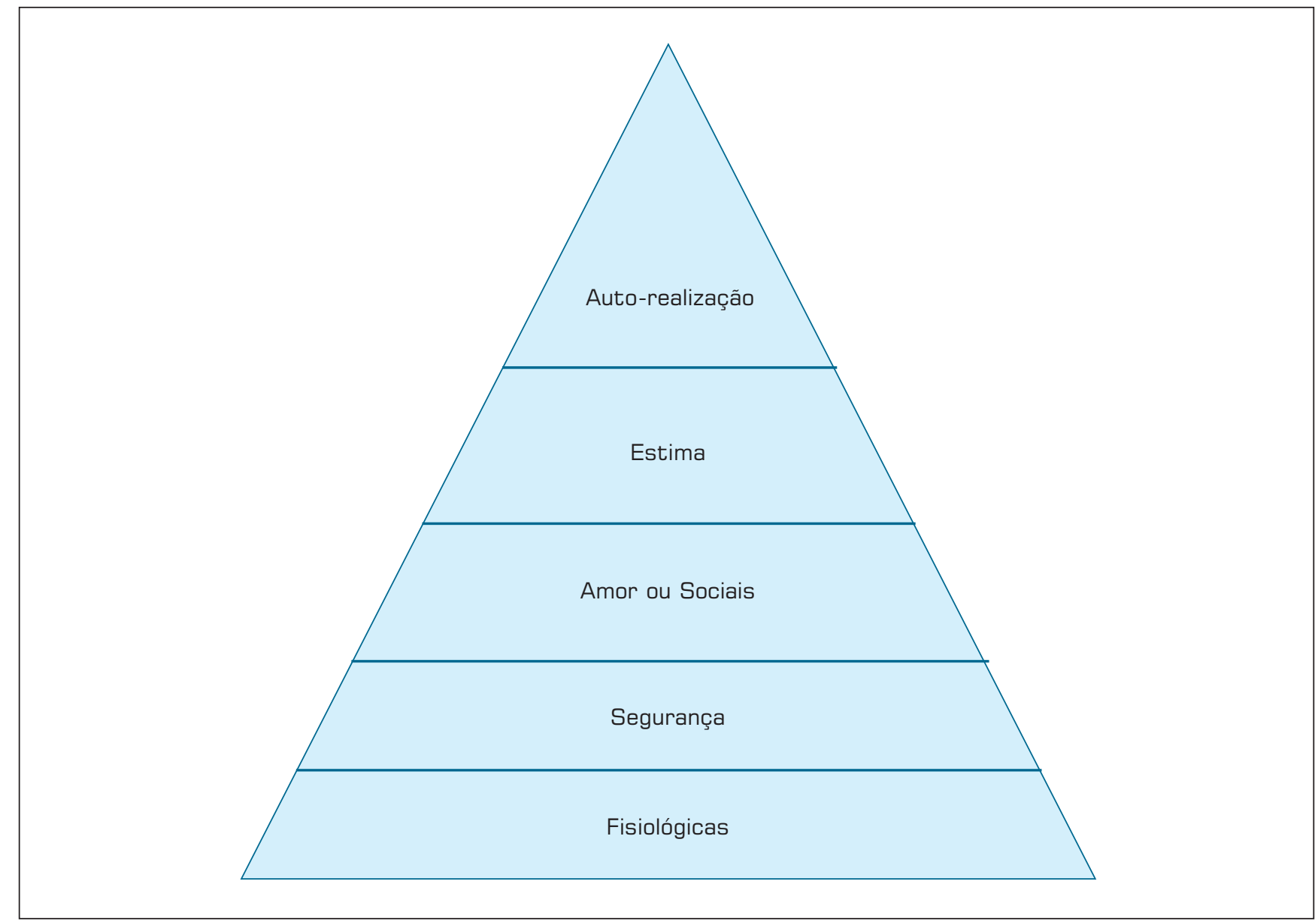


determina sua percepção do relacionamento, que poderá ser observado como satisfatório para as pessoas que percebem que suas recompensas excederam as demandas feitas sobre elas. O indivíduo ingressa na organização quando espera que as suas satisfações pessoais sejam maiores que seus esforços pessoais. Se acredita que seus esforços pessoais ultrapassem as satisfações, torna-se propenso a abandonar a organização, se possível.

Ao mesmo tempo, a organização espera que a contribuição de cada indivíduo ultrapasse os custos de ter pessoas na organização. Em outros termos, a organização espera que os indivíduos contribuam mais do que ela lhes dá.

Os processos mentais e emocionais na ação desempenhada no contexto socioprofissional, através dos contratos psicológicos, deverão ser reavaliados para o próximo século organizacional. Segundo Kanaane (1999), deverá ser levado em consideração um novo estágio de desenvolvimento organizacional, considerando a qualidade de vida do trabalhador e seu grau de integração ao trabalho e à organização a que pertence.

... todo dirigente terá que considerar que as pessoas que lhe são subordinadas hierarquicamente, e ele próprio, são seres inacabados, incompletos, com possibilidades de crescimento e aprimoramento constante em termos de relacionamento humano e interpessoal, além da capacitação técnica (KANAANE, 1999, p. 124).

Para a manutenção dos talentos de uma organização, é necessário que os especialistas de recursos humanos assumam algumas medidas, desde as relacionadas aos fatores materiais, como espaço físico, quantidade e volume de trabalho, higiene e segurança do trabalho e salário, até as co-relacionadas à organização social do trabalho, como: o estilo de liderança, o processo de delegação, as perspectivas de participação nas decisões, sinergia entre setores e departamentos e outras vinculadas à dinâmica da organização.

Neste contexto, faz-se urgente o rompimento dos métodos tradicionais de recursos humanos, em prol de uma redefinição das técnicas de gestão da empresa e da administração de recursos humanos.

Kanaane (1999, p. 125), apresenta algumas propostas para as empresas que almejam ingressar no primeiro mundo:

Fundamentalmente precisa ser definido um plano de educação para o país. Somente através da maior qualificação de nossos Recursos Humanos poderemos almejar melhores posições no quadro nacional.

A educação do ponto de vista tecnicista é apenas um dos elementos do processo de formação. Ela deve ser encarada sob um enfoque mais amplo, ao permitir melhor formação sob o prisma sociocultural, também. Trata-se, de fato, de um processo amplo que deve visar especialmente o enriquecimento da qualidade de vida do indivíduo, que dessa forma, melhor habilitado e inserido em seu meio, poderá gerar maiores resultados do ponto de vista da qualidade total. A proposta nesse momento é de amparo maior por parte das organizações, pelo menos a curto e médio prazo, quando o país ainda se mostra despreparado para atender a esses anseios.

No nível da empresa, a implantação de sistemas participativos centrados no indivíduo é urgente. Só com transparência e comunicação poderemos almejar a qualidade total.

A Administração de Recursos Humanos deve ser mais bem valorizada, ser sistêmica, coesa não só pelos seus profissionais, mas sobretudo pela cúpula diretiva das organizações. Só com Administração de Recursos Humanos plenamente inserida no processo decisório é que se poderão esperar claras políticas e estratégias de adequação à nova realidade.

Compartilhamento das responsabilidades de Administração de Recursos Humanos com todos os indivíduos da empresa, sobretudo com aqueles que ocupam cargos de liderança. Assim, toda a organização passará a agir em conjunto numa única direção, claramente definida quando da criação de políticas de Administração de Recursos Humanos.

Os desafios impostos para o século XXI requerem posturas diferenciadas na valorização do indivíduo; espera-se das organizações a facilitação para o indivíduo alcançar sua plenitude, e conviver com a velocidade do mundo, sem perder sua identidade como indivíduo, cidadão e profissional. De acordo com Kanaane (1999), "a implementação desta proposta é contemporânea, sendo árdua, mas necessária, pois do contrário inviabilizar-se-ão a sociedade, as organizações e o próprio homem" (p. 126).

\section{CONCLUSÃO}

Com a apresentação deste quadro poderíamos concluir que o caminho para o sucesso de todas as partes no processo empresarial seria a adequação dos relacionamentos, indicando uma necessária mudança no campo organizacional direcionando-se para as práticas da individualização, no mesmo princípio da mais moderna metodologia do marketing um a um.

A mudança organizacional não ocorre por si só, essa mudança depende das pessoas e do sistema de gerenciamento praticado. Apesar da área de recursos humanos lidar com as pessoas, quase todo seu tempo recrutando-as, selecionando-as, treinando-as, cuidando dos seus benefícios e desligando-as, não há gerenciamento de recursos humanos individualizado. Mantêm a mesma linha conceitual do $m a$ rketing de massa, gerenciando apenas seus produtos e serviços, pouco colhendo informações detalhadas das expectativas e níveis de satisfação. 
Em nenhum momento dessa relação individualizada com o seu cliente ou colaborador, poderão a área e profissionais de recursos humanos quebrar duas importantes regras de relacionamento: a confiança e a privacidade das informações individuais.

Os autores Peppers \& Rogers (1996, p. 299) dizem, em seu livro Marketing Um a Um: "A confidencialidade é como a virgindade: uma vez perdida, é para sempre".

Para a área de recursos humanos gerar essa confiança, ela terá que buscar uma maneira de tranqüilizar o seu cliente de que as informações com as quais ele estiver colaborando, não serão transgredidas e não sofrerão abuso. Terá que encontrar meios de assegurar ao seu cliente que as informações enviadas serão relevantes e discretas e que as informações serão usadas somente para o seu próprio benefício.

Segundo Kotler (2000, p. 35), “em mercados altamente competitivos, todos os departamentos têm de se concentrar na conquista da preferência do cliente. Jack Welch, o célebre presidente da General Electric, diz a seus funcionários: "As empresas não podem garantir a vocês estabilidade no trabalho. Isso é algo que só os clientes podem fazer!’.

Faith Popcorn, considerada a Nostradamus do marketing, em seu artigo "Do casulo às 99 vidas", destaca que os colaboradores não trabalham apenas pelo dinheiro; também querem recuperar seu tempo e se sentirem valorizados. Querem dar para receber. Qualquer companhia que deseje ter sucesso no futuro, deve desenvolver uma relação muito estreita com seus colaboradores: saber como é cada pessoa, que tipo de vida tem, como é sua mulher ou o seu marido, como são seus filhos, quais os objetivos que essa pessoa tem na vida.

Além disso, a empresa tem a responsabilidade de oferecer a seus colaboradores algum tipo de bem-estar. Bemestar, além do conceito convencional, significa, para as pessoas, trabalhar em alguma coisa de que gostem, que lhes dê a possibilidade de desenvolvimento pessoal. Significa também sentir que a empresa ajudará quando o colaborador enfrentar uma crise, que ela se preocupará com sua saúde e com seu futuro. Ou seja, a gestão de recursos humanos terá que desenvolver soluções totais para seus talentos permanecerem na empresa.

As empresas mais bem-sucedidas serão aquelas que estabelecerem os relacionamentos mais profundos, mais confiáveis, com seus clientes e colaboradores individuais, devendo seguir uma simples filosofia: o seu cliente falará, e você ouvirá; o seu cliente pedirá, e vocês dois farão juntos.

A nova administração individualizada de recursos humanos deverá transformar o sistema de gerenciamento e tratamento em grupo/massa, para uma gestão e gerenciamento de cliente individualizado, transformando completamente os conceitos de gestão de pessoas nas empresas, retendo os principais patrimônios, seus talentos e o lucro.

\section{- Bibliografia}

ARGYRIS, C. A integração indivíduoorganização. São Paulo: Atlas, 1975.

BALCÃO, Y.F.; CORDEIRO, L.L. O comportamento humano na empresa. Rio de Janeiro: Fundação Getulio Vargas, 1975.

CAPRA, F. 0 ponto de mutação. São Paulo: Cultrix, 1982

CARAVANTES, G.R. Recursos humanos estratégicos para o $3^{\circ}$ milênio. Rio Grande do Sul: CENEX e FACTEC, 1993.

Teoria geral da administração: pensando \& fazendo. Porto Alegre: AGE 1998.

CHANLAT, J.F. 0 indivíduo na organização. São Paulo: Atlas, 1993.

CHARDIN, T. de. O fenômeno humano. São Paulo: Cultrix, 1993.

CHIAVENATO, I. Introdução à teoria geral da administração. Rio de Janeiro: Campus, 2000.

. Gerenciando pessoas: o passo decisivo para a administração participativa. São Paulo: Makron Books, 1992.
DRUCKER, P.F. As fronteiras da administração: onde as decisões do amanhã estão sendo determinadas hoje. São Paulo: Pioneira, 1989.

As novas realidades: no governo e na política, na economia e nas empresas, na sociedade e na visão do mundo. São Paulo: Pioneira, 1989.

CURY, A. Organização e métodos: uma visão holística. São Paulo: Atlas, 2000.

GALBRAITH, J.K. A era da incerteza. São Paulo: Pioneira, 1986.

KANAANE, R. Comportamento humano nas organizações: o homem rumo ao século XXI. São Paulo: Atlas, 1999.

KOTLER, P. Administração de marketing: análise, planejamento, implementação e controle. São Paulo: Atlas, 1996.

Marketing para o século XXI: como criar, conquistar e dominar mercados. São Paulo: Futura, 2000.
MORAES, J.G.V. de. Caminhos da civilização: história integrada geral e Brasil. São Paulo: Atual, 1998.

PEPPERS, D.; ROGERS, M. Empresa 1:1: instrumentos para competir na era da interatividade. Rio de Janeiro: Campus, 1997.

Marketing um a um: marketing individualizado na era do cliente. Rio de Janeiro: Campus, 1996.

POPCORN, F. Do casulo às 99 vidas. HSM Management, setembro-outubro, 1998.

PREDEBON, J. Criatividade hoje: como se pratica, aprende e ensina. São Paulo: Atlas, 1999.

RABUSKE, Edvino A. Antropologia filosófica. Petrópolis: Vozes, 1986 .

ROBBINS, S.P. Comportamento organizacional. Rio de Janeiro - LTC 1999
RUBIO, F. V. Introdução ao projeto de pesquisa científica. Rio de Janeiro: Vozes, 1982

SCHELER, Max. Visão filosófica do mundo. São Paulo: Perspectiva, 1986.

TOLEDo, F. de. Administração de pessoal: desenvolvimento de recursos humanos. São Paulo: Atlas, 1989.

VAZ, H.C. de L. Antropologia filosófica I e II. São Paulo: Loyola, 1992.

WAGNER III J.A.; HOLLENBECK J.R. Comportamento organizacional: criando vantagem competitiva. São Paulo: Saraiva, 2000

WERTHER, W.B.J.; DAVIS, K. Administração de pessoal e recursos humanos. São Paulo: McGraw-Hill, 1983. 